\title{
Globalização, gestão e acesso aos sistemas público e privado de saúde: a Baixada Fluminense no contexto da pandemia
}

Mondialisation, gestion et l'accès aux systèmes de santé publique et privé : la Baixada Fluminense dans le contexte de la pandémie

Globalization, management, and access to the public and private health systems:

Baixada Fluminense in the context of pandemic

Globalización, gestión y acceso a los sistemas de salud públicos y privados: la Baixada Fluminense en el contexto de la pandemia.

\section{André Santos da Rocha}

\section{(2) OpenEdition}

\section{Journals}

\section{Edição electrónica}

URL: http://journals.openedition.org/espacoeconomia/12672

DOI: 10.4000/espacoeconomia.12672

ISSN: 2317-7837

\section{Editora}

Núcleo de Pesquisa Espaço \& Economia

Refêrencia eletrónica

André Santos da Rocha, « Globalização, gestão e acesso aos sistemas público e privado de saúde: a Baixada Fluminense no contexto da pandemia », Espaço e Economia [Online], 18| 2020, posto online no dia 20 abril 2020, consultado o 20 maio 2020. URL : http://journals.openedition.org/ espacoeconomia/12672; DOI : https://doi.org/10.4000/espacoeconomia.12672

Este documento foi criado de forma automática no dia 20 maio 2020

(C) NUPEE 


\title{
Globalização, gestão e acesso aos
} sistemas público e privado de saúde: a Baixada Fluminense no contexto da pandemia

\author{
Mondialisation, gestion et l'accès aux systèmes de santé publique et privé : la \\ Baixada Fluminense dans le contexte de la pandémie \\ Globalization, management, and access to the public and private health systems: \\ Baixada Fluminense in the context of pandemic \\ Globalización, gestión y acceso a los sistemas de salud públicos y privados: la \\ Baixada Fluminense en el contexto de la pandemia.
}

André Santos da Rocha

\section{Introdução}

1 No mundo contemporâneo vivenciamos fenômenos e eventos cada vez mais globais que possuem fortes repercussões nas escalas locais, com os lugares denunciando, ao seu modo, essa globalidade. "Lugares são, à sua maneira, o mundo" (SANTOS, 2002, p.314), pois neles estão contidos os lastros da vida cotidiana, das práticas políticas do Estado e de outros atores. Além disso, eles exemplificam a circularidade de mercadorias, ideias e informações mundiais recriando, a partir de suas próprias condições, uma nova geografia da globalidade-mundo no lugar.

Por exemplo, os avanços da COVID-19 e o reconhecimento por parte da Organização Mundial de Saúde (OMS) do estágio de pandemia em 11 de março de $2020^{1}$, nos forçam a traçar algumas reflexões sobre seus desdobramentos e a avaliar as condições que o modo de pensar e produzir no enredo da globalização se efetiva neste lugares. Neste caso, como a forma de pensar os sistemas de saúde, a distribuição de equipamentos e, em especial o número de leitos em municípios da periferia metropolitana, permitem 
denunciar modelos injustos e ineficazes de gestão econômica na política pública? Outrossim, como as conexões entre os modelos de privatização da saúde vão na contramão da resolução dos impactos de doenças globais como é o caso da COVID-19, que possui alto grau de contágio e rápida disseminação do vírus? Como, do ponto de vista geográfico, os municípios das periferias urbanas no Brasil darão respostas a esta questão?

3 No sentido de realizar esta análise, nosso quadro teórico-analítico reside sobre a natureza da gestão neoliberal, admitindo-a como um modus operandi da globalização que aponta a privatização como modelo de gestão da saúde em níveis mundiais. Tomando os recentes relatórios da OMS e da Organização Pan-Americana de Saúde (OPAS) a fim de demonstrar um ciclo de desinvestimento nos países e, assim, fundamentar como o Estado faz a gestão das políticas públicas de saúde como parte de uma agenda neoliberal. Por sua vez, o setor privado não consegue atender, na lógica econômica da demanda-procura, as necessidades básicas cotidianas - muito menos em tempos de colapso - produzindo, portanto, um ciclo de injustiças territoriais, uma vez que as áreas mais periféricas e a população menos favorecida são fortemente atingidas por essas políticas neoliberais.

4 No tocante ao estudo de caso, na segunda parte analisaremos os dados do sistema de saúde (DATASUS) referentes ao número de leitos nos municípios da Baixada Fluminense (RJ) e ao avanço da COVID-19. Esses evidenciam como as políticas neoliberais provocaram o desinvestimento e, consequentemente, a diminuição no número de leitos, bem como uma distribuição desigual de recursos hospitalares sobre o território a qual o setor privado é incapaz de atender. De modo conclusivo, essa análise implica na necessidade de se repensar o acesso às políticas de saúde a partir de sua universalização e com inteligência territorial.

\section{A Globalização, o pensamento neoliberal e seus desdobramentos para as políticas de saúde}

5 Para fins básicos entendemos que a globalização corresponde ao ápice da economia capitalista (SANTOS, 2007), que este modelo de produção é hegemônico (JAMESON, 2001) e se revela com seu par dialético, o processo de fragmentação (HAESBAERT, 2013). A circularidade das mercadorias em nível mundial, o aumento da capacidade de conexão entre os lugares, a elevação dos fluxos migratórios (temporários ou permanentes) entre os continentes e a presença massiva das redes sociais como elementos de interação e níveis planetários evidenciam um período marcado por esse contexto da globalização.

6 Para Milton Santos, essa globalização - a despeito das inovações técnicas que permitem pensar os ares de uma "sociedade mundial integrada", de "cidadanias globais", ou mesmo de uma fraternidade cultural mundial que poderia fundamentar uma "Globalização como fábula" ou como o protoprojeto de futuro benéfico, "a Globalização como ela poderia ser" - tem se revelado, na prática, como perversidade. Isso porque o dinheiro é o seu principal pilar. Em uma análise apurada, a tecnologia, a informação e o dinheiro, quando conjugados, são os núcleos das transformações recentes que fundamentam a reprodução do atual contexto. Todavia é o dinheiro a 
âncora deste contexto, uma vez que ele é, ao mesmo tempo, "pilar e motor único" (SANTOS, 2007, p.29-30).

7 A lógica de acumulação tem fundamentado as formas de gestão e execução que influenciam ordinariamente a vida cotidiana e, por isso, produtora de assimetrias nos lugares. E ela tornou-se assim porque alcançamos um "novo patamar da internacionalização", que marca uma "verdadeira mundialização do produto, do dinheiro, do crédito, da dívida, do consumo e da informação". Essa conjuntura da globalização não é apenas econômica - no sentido do que está inserida é apenas parte da produção-circulação e consumo (HARVEY, 2009), mas eminentemente política porque congrega ações de atores que, co-ordenamente, contribuíram para sua arquitetura, legitimidade e regulação (NEGRI, 2004).

8 No interior desta legitimidade reside o balizador da forma de gestão que é contida, segundo Frederic Jamenson (2000, p.145) na "retórica glorificadora da globalização e do livre comércio nos Estado Unidos" as quais, segundo o autor, são as bases da "teoria neoliberal". De toda forma, torna-se cada vez mais difícil tentar definir o neoliberalismo dado, por vezes, o uso indevido do termo como instrumento que se aplica em diferentes abordagens, versões e visões (ANDRADE, 2019). Ele é mencionado por políticas de Estados democráticos e autoritários. Ao mesmo tempo parte do berço de economias capitalistas como a estadunidense quanto das estratégias de ação da China - para alguns, uma espécie de socialismo de mercado, porém, para David Harvey, representa apenas a feição do neoliberalismo (HARVEY, 2008) Este termo pode ser referir ao mesmo tempo à forma como um governo rege suas políticas em níveis estatais e à forma implícita sobre como ele influencia as lógicas da vida banal (DARDOT \& LAVAL, 2009).

De todo modo, concordaremos aqui em entendê-lo de modo transescalar a partir de um contexto geoeconômico e geopolítico. Em primeiro lugar porque ele se desenha como uma série de estratégias econômicas que busca permitir maior fluidez e volatilidade para a circulação do capital e de sua acumulação, que atravessa desde ações do Estado, passa pelas grandes corporações em suas tomadas a partir de modelo de gestão financeira e empresarial até os níveis mais sensíveis da vida humana. E, em segundo lugar, porque o neoliberalismo se alinha às estratégias de desenvolvimento e expansão geográfica imputando a organização dos países a partir de preceitos globalizadores.

Como exemplo geoeconômico e geopolítico, o "Consenso de Washington" (1989) desenhou as políticas de desenvolvimentos que se territorializaram em toda América Latina nas décadas seguintes, anos de 1990 e 2000 (MAMIGONIAN, 2006). Esse é, em resumo, uma série de ações que os países deveriam seguir para alcançar êxito na escalada do desenvolvimento, estando, portanto, alinhadas ao padrão neoliberal de "como fazer sua gestão". De acordo com Bresser-Pereira (1990, p.5), esse "consenso" pode ser interpretado como um agregado de dez medidas, que tem origem nas interpretações de "Williamson (1990), um proeminente economista do Institute for International Economics, que escreveu um artigo que serviu de base para um seminário internacional e para a publicação de um livro, no qual definiu o que chamou de o consenso de Washington" ${ }^{2}$. Dentre essas dez medidas, entendemos que três delas são as que mais produzem impactos diretos sobre o modo de pensar a gestão das políticas públicas de forma geral, e que criam um terreno árido para as políticas de saúde: a disciplina fiscal, a redução dos gastos públicos e a privatização das estatais. 
11 Essa tríade torna-se algoz não apenas da saúde na América Latina, mas de todo o sistema público de saúde mundial, uma vez que são incorporadas como estratégias do setor público na tentativa de minimizar os gastos com pessoal e equipamentos tendo como finalidade evitar o estrangulamento fiscal e tentar reduzir gastos públicos com investimentos nas políticas de saúde - vide o exemplo de 2017, quando foi votada no Brasil a PEC 241 (a qual mais tarde se tornaria a Emenda Constitucional 95) referente ao teto dos gastos públicos por vinte anos ${ }^{3}$, medida que produzirá impactos em políticas que traduzem direitos fundamentais como saúde e educação, direitos que atendem a todos os cidadãos. Outrossim, não se pode ignorar que as estratégias do setor privado que, em termos práticos de maximização de lucros, produz considerável impacto para o campo da saúde. Uma vez que o modelo de gestão baseado na perspectiva da potencialização e do uso do material investido (equipamentos, pessoal, leitos, medicamentos) desconsidera a demanda social do campo da saúde, ou seja, não a entende como um direito essencial à vida humana mas como um serviço, ela é interpretada como mercadoria e vai perdendo o sentido de direitos humanos.

Em nossa perspectiva, pensar a aplicação dos direitos é uma condição sine qua non para a efetividade das políticas públicas (ROCHA, 2012) e das garantias de condição da cidadania (SANTOS, 2007b). Assim, ao passo que o sistema de Saúde se torna mercadoria, e não direito, a dimensão mais voraz da faceta desta globalização perversa é sublinhada (SANTOS, 2007), uma vez que o dinheiro passa a ter maior valor que a vida humana - revelando as assimetrias de nossa sociedade e os descasos sociais.

O que nos chama atenção é que essa condição tanto do setor público quanto do privado não se restringe aos países latino-americanos ou aos do Sul Global como um todo. Ela evidencia a globalidade de mercantilização da saúde, responsável por provocar efeitos negativos sobre toda a sociedade. Como exemplo destas tendências, Mike Davis (2020, p. 8) informa dados do cenário norte-americano:

De acordo com a Associação Hospitalar Americana, o número de leitos hospitalares diminuiu extraordinariamente em 39\% entre 1981 e 1999. O objetivo era aumentar os lucros aumentando o "censo" (o número de leitos ocupados). Mas a meta da gerência de 90\% de ocupação significava que os hospitais não tinham mais capacidade de absorver o fluxo de pacientes durante epidemias e emergências médicas (2020, p.8).

15 Assim, os preceitos gerenciais de produtividade de gestão quando aplicados às políticas de saúde não consideram a saúde como direito. Por exemplo, no tocante à interpretação da pandemia atual, o mesmo Mike Davis destaca que nos Estados Unidos apenas oitos estados teriam leitos suficientes para lidar com os afetados pela COVID-19 com mais de 60 anos. A adoção de medidas neoliberalizantes no campo da saúde impactou sensivelmente o número de leitos nos Estado Unidos, "três vezes menor que na Coréia do Sul" (ibidem, p.8); ele ainda reforça que " $45 \%$ da força de trabalho não tem esse direito" a sistema de saúde e "é praticamente obrigada a transmitir a infecção ou ficar com o prato vazio" (ibidem, p.9).

16 Não por acaso, ao monitorar as tendências globais nos gastos com saúde a OMS (2018) percebeu transformações no sistema de financiamento mundial de serviços de saúde. Intitulado Public spending on health: a closer look at global trends ${ }^{4}$, seu relatório destaca que os gastos totais com saúde estão crescendo mais rápido do que o produto interno bruto, sendo que esse aumento é mais rápido em países de baixa e média renda (perto de $6 \%$ em média) do que em países de alta renda (4\%). Segundo a OMS, no ano de 2016 “o mundo gastou US\$ 7,5 trilhões em saúde, representando cerca de 10\% do PIB global. 
A média do gasto com saúde per capita foi de US\$ 1.000 , mas metade dos países do mundo gastou menos mais de US\$350 por pessoa" $\left(2018\right.$, p.3) ${ }^{5}$.

O referido estudo reafirma a importância dos gastos do Estado para "manutenção da cobertura universal da saúde", sobretudo com a finalidade de mitigar a inacessibilidade em momentos de crise. A maior parte dos gastos de saúde no mundo ainda provem de fundos governos dos países, todavia há ainda uma considerável quantia que é paga a partir de fundos próprios dos habitantes o que incluem participação de planos ou seguros saúde ou gastos diretos. Segundo a OMS (2018, p.3):

"Os governos fornecem uma média de $51 \%$ dos gastos com saúde de um país, enquanto mais de $35 \%$ dessas despesas são pagas pelas pessoas com o próprio dinheiro. Isso leva 100 milhões de pessoas à extrema pobreza a cada ano [...] em média, os governos gastam US\$ 60 por pessoa em saúde nos países de baixa-média renda e aproximadamente US $\$ 270$ por pessoa nos países de média-alta renda" 6 .

Sensivelmente, as assimetrias da performance dos gastos com saúde acompanham a linha abissal norte-sul (SOUZA SANTOS, 2010), uma vez que em países onde a renda é mais alta, ou seja, os do "norte global", conseguem produzir maiores gastos com sistema de saúde, ao passo que os do Sul global agonizam com os preceitos neoliberais que asfixiam o setor de investimento - marcado, cumpre reiterar, pela tríade redução dos gastos públicos, ajuste fiscal e privatizações.

Ainda conforme dados disponibilizados pela OMS, "mais de $80 \%$ da população mundial vive em países de baixa e média (Sul Global), mas representam apenas $20 \%$ gastos com saúde em 2016 do mundo" [ver Imagem 1]

Imagem 1 - Gráfico da População global e gastos com saúde distribuídos por país - grupo de renda, 2016

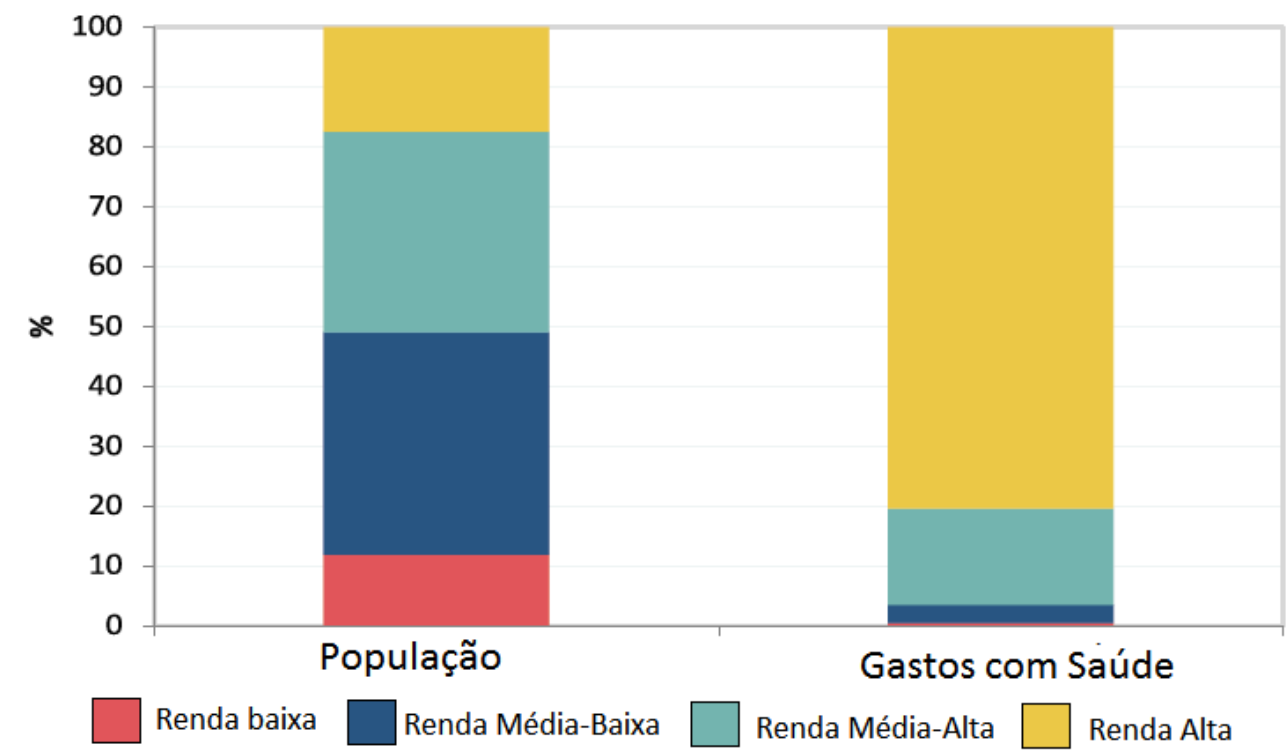

Fonte: OMS (2018, p.6). Adaptação (tradução do Autor)

Em síntese, podemos observar a existência de uma grande desigualdade global no acesso ao sistema de saúde e na capacidade de pagar por ele. No contexto da globalização neoliberal tanto as assimetrias territoriais quanto a divisão internacional do trabalho são acentuadas. A equação é simples: para terem o mínimo de acesso ao 
sistema saúde, diversas pessoas, em especial nos países mais pobres, necessitam arcar com os custos médicos, o que os deixa ainda mais pobres. É por isso que o mesmo relatório indica que "quanto maior for o gasto público com saúde, maior será a segurança financeira de seus habitantes" (OMS, 2018, p.1). Neste contexto, o último relatório da OPAS, intitulado Situación de la salud en las Américas: indicadores básicos ${ }^{7}$ revela que os países latino-americanos investem em média cerca de 5\% do PIB, taxa menor que a recomendada pela OMS, estando portando abaixo de $6 \%$ - patamar que permitiria maior acesso à cobertura universal de saúde. No relatório em tela, em 2015 o governo brasileiro investiu cerca de 3,8\% do PIB; em contrapartida, o gasto do setor privado foi referente a $5 \%$ do PIB. O avanço do investimento privado no campo da saúde no Brasil é solidificado com o que se chama de desoneração fiscal, a qual tem aumentado ano a ano. Essa desoneração compreende a dedução dos impostos para gastos privados com saúde de pessoa física, jurídica e hospitais de filantropia e medicamentos e produtos químicos. Se somados esses gastos com desoneração, perceberemos que em 2003 o valor era de 17 bilhões de reais, passando em 2015 para 32,21 bilhões de reais ${ }^{8}$.

23 A consequência nefasta é a de que estamos a caminho de um modelo cada vez mais desigual no acesso à saúde. Nas palavras do pesquisador do IPEA Carlos Ocké: "De um lado, você sucateia o SUS ao congelar os gastos; de outro, não põe limite para repasses indiretos às operadoras. Assim, você força as pessoas a irem para o setor privado, estimulando a privatização da saúde" 9 .

Todo esse debate aponta para o papel da cobertura universal, a qual deve ser entendida como um pilar dos direitos humanos e não uma mercadoria a ser negociada. Isso tem reflexos diretos na condição econômica e política das sociedades e na forma como lidaremos com impactos (im) previsíveis como os da Covid-19. Os efeitos do modelo neoliberal gerado nas escalas nacionais e globais, revelados pelas contradições dos lugares, consegue reforçar o alcance das assimetrias.

Neste sentido, frente ao avanço da Covid-19, se torna válido fazer um diagnóstico do sistema de saúde na periferia metropolitana do Rio de janeiro, conhecida popularmente como Baixada Fluminense. Esse recorte espacial permite ver os impactos nas escalas municipais, mas também o desenrolar dos impactos do sistema de saúde nestas localidades.

\section{Políticas públicas de saúde e avanço da Covid-19: diagnóstico geográfico sobre a Baixada Fluminense}

No início do mês de abril de $2020{ }^{10}$, o Estado do Rio de Janeiro é o segundo país em números de infectados. Segundo a Secretaria Estadual de Saúde, no dia 14 do referido mês foram contabilizados 3410 infectados e confirmados 224 óbitos. Se somarmos os casos da Cidade do Rio de Janeiro e da Baixada Fluminense teríamos mais de 80\% dos casos do Estado, reiterando seu caráter urbano-metropolitano e, sobretudo, a pressão sobre as periferias.

Como já mencionado por diferentes jornais, pela comunidade acadêmica e órgãos oficiais, o grande desafio dessa doença é a facilidade de transmissão e sua rápida propagação, cujo tratamento pode requerer medidas intensivas com internações que intensificam a lotação de leitos gerais e de UTI e a necessidade de intubação de 
pacientes - o que amplia o uso de aparelhos respiratórios. Essa pressão sobre o sistema de saúde pode ser dramática para a realidade da Baixada Fluminense e promover a ampliação do número de óbitos.

Em nossos estudos concebemos a Baixada Fluminense como uma região formada pelos municípios de Guapimirim, Magé, Duque de Caxias, Nova Iguaçu, Belford Roxo, São João de Meriti, Nilópolis, Mesquita, Belford Roxo, Queimados, Japeri, Paracambi, Seropédica e Itaguaí. Popularmente conhecida por uma representação hegemônica que a associa à pobreza, à violência e ao descaso social, estamos diante de uma periferia fortemente conurbada com a cidade do Rio de Janeiro marcada por intenso adensamento populacional e problemas sociais e de infraestrutura graves.

Essa regionalização corresponde ao espaço incorporado à "célula urbana do Rio de Janeiro" ao longo do século XX da porção central e oeste da metrópole carioca (SEGADA SOARES, 1962), à "Baixada política" mencionada por Manoel Simões (SIMÕES 2007) e a "representação ideal de um território", forjado pelos interesses de políticos da região em consonância com os projetos de atores econômicos e que recebeu novas ondas de crescimento econômico a partir dos anos 2000 (ROCHA, 2014). Apesar de todos os investimentos no setor industrial e imobiliário entre 2000 e 2014 (ROCHA, 2015; OLIVEIRA, 2015) terem levado a FIRJAN a projetar essa região no ano de 2007 como a que impulsionaria o desenvolvimento do Estado do Rio de Janeiro, tal crescimento econômico não foi suficiente para promoção de políticas de equidade e reparadoras para grande maioria da população - o que pode ampliar os problemas estruturais em tempos de pandemia.

Segundo Alexandre Fortes e Leandro Dias de Oliveira (2020) ${ }^{11}$, o avanço da Covid-19 na periferia metropolitana do Rio de janeiro pode revelar um "verdadeiro tsunami", porque há inúmeras fragilidades socioeconômicas características dessa realidade territorial. Conforme estudo da Fundação Perseu Abramo (2020, p.14-17) ${ }^{12}$, pelo menos quatro municípios da Baixada estão entres os trinta com maior vulnerabilidade à disseminação do vírus: São João de Meriti (1º posição), Nilópolis (4º posição), Belford Roxo ( $9^{\circ}$ posição) e Mesquita ( $21^{\circ}$ posição). Trata-se de municípios que estão exatamente no "umbigo" da conurbação metropolitana com o Rio de Janeiro e essa espacialidade traduz um pouco da realidade presente nos demais municípios desta periferia metropolitana. Além do forte adensamento populacional e problemas nas condições de moradia, possuem políticas de saúde aquém das demandas existentes, um mercado de trabalho informal e de subemprego crescente e um sistema sanitário precarizado. Tais fatores potencializam a disseminação da doença e demandam políticas públicas eficientes.

Quando pensamos políticas públicas estamos nos referindo a ações que servem para intervir na realidade socioespacial e efetivar direitos, que são por si próprios integrais, indivisíveis e universais (ROCHA, 2012). É neste sentido que em tempos de pandemia se faz urgente pensar as políticas públicas de saúde que, particularmente, permitem que nos apropriemos da possibilidade da manutenção da vida humana e de sua qualidade, bem como da proteção, da promoção e da reparação dos direitos (BARBOSA, 2008).

O crescimento de números de casos da Covid-19 - em sua maioria subnotificados nos municípios da Baixada - até a escrita deste texto contabilizavam 359 casos ${ }^{13}$, o que nos leva a pensar as fragilidades do sistema de saúde e a ocorrência da seletividade espacial das políticas públicas capazes de exprimir a desestruturação dos territórios - 
sobretudo porque pensar os impactos dessa doença nos território envolve analisar uma geografia do número de leitos disponíveis.

Segundo os dados do DATASUS, tendo como referência o mês de março de 2020, foram identificados 4089 leitos [de uso geral e UTI's] somando-se todos os municípios da Baixada Fluminense. Com base nas estimativas do IBGE, em 2019 os treze municípios da Baixada Fluminense ${ }^{14}$ totalizam 3.890 .887 habitantes. Isso significa uma proporção de 1,05 leitos para cada 1.000 habitantes. Segundo a OMS o ideal seria ter uma média de 3 a 5 leitos por 1.000 habitantes, sendo a média mundial atualmente 3,2. Para se ter uma ideia, a Itália, que durante um bom tempo foi o grande epicentro da doença, possui a média de 3,18, ou seja, $60 \%$ mais leitos que no Brasil, cuja média é 1,98.

Esses dados refletem uma tendência que atinge também o Estado do Rio de janeiro. Segundo informações do IBGE, houve um decréscimo no número de leitos entre os anos de 1990 e 2009 [Imagem 2]. Os efeitos da gestão do estado neoliberal refletem uma gradativa piora do quadro no Estado do Rio de Janeiro.

Imagem 2 - Involução da relação de leitos por 1000 habitantes no Estado do Rio de janeiro (1990-2009)

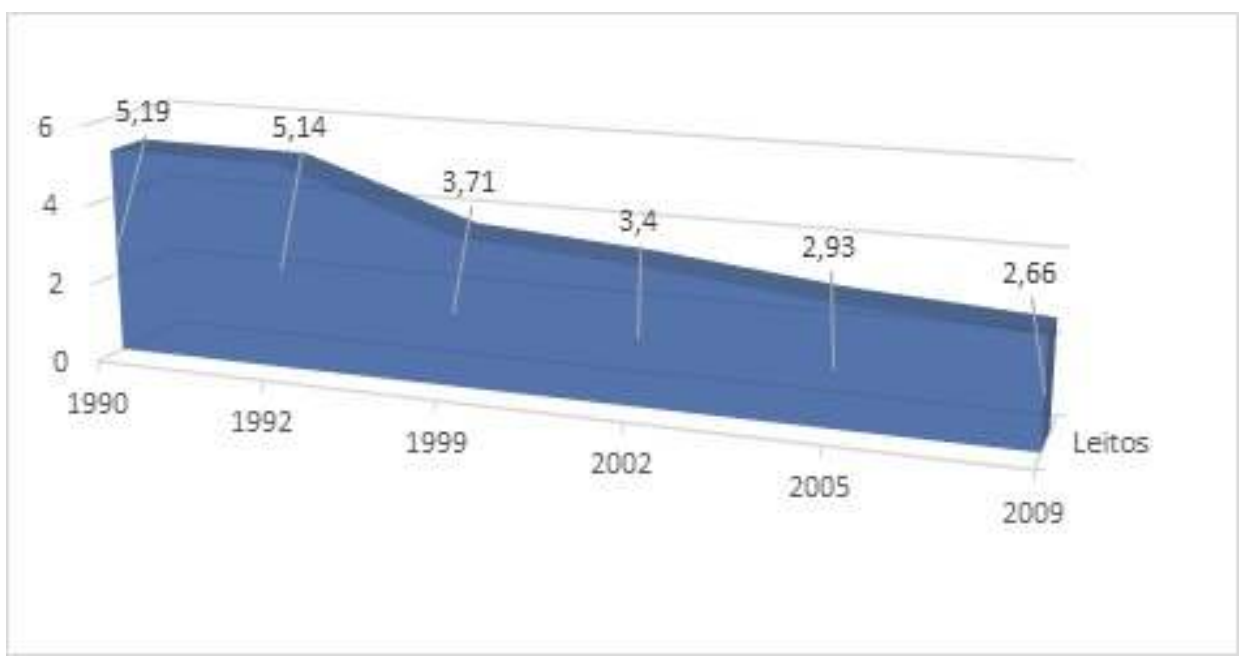

Fonte: IBGE CIDADES, organização do autor.

Se considerarmos os números atuais do DATASUS [referente a março de 2020] ${ }^{15}$, o estado do Rio de Janeiro conta hoje com 42.137 leitos, sendo que destes apenas 8.745 são de UTI. Em 2019, a população do Estado estava estimada em 17.264.943 pessoas, isto é, uma média de 2,44 leitos para cada mil habitantes - menor que a média registrada em 2009. A situação é bem mais grave se pensarmos na acessibilidade da população no tratamento das formas agudas da covid-19, pois aproximadamente cerca de $69,86 \%$ dos leitos de UTI não são pertencentes ao SUS. Isso reverbera os efeitos nocivos de uma política de desinvestimento contribuindo, assim, para ampliar os casos de letalidade no avanço da doença.

Quando olhamos para a realidade do Sistema de Saúde da Baixada Fluminense podemos ter uma noção do que se trata esse impacto. Destaque-se que os números contabilizados levam em consideração tanto os leitos do SUS quanto os pertencentes ao sistema privado [ver imagem 3].

Imagem 3 - Mapa da Quantidade do número de Leitos [Uso Geral+UTI] com proporção pertencente ao SUS e a rede privada na Baixada Fluminense. 


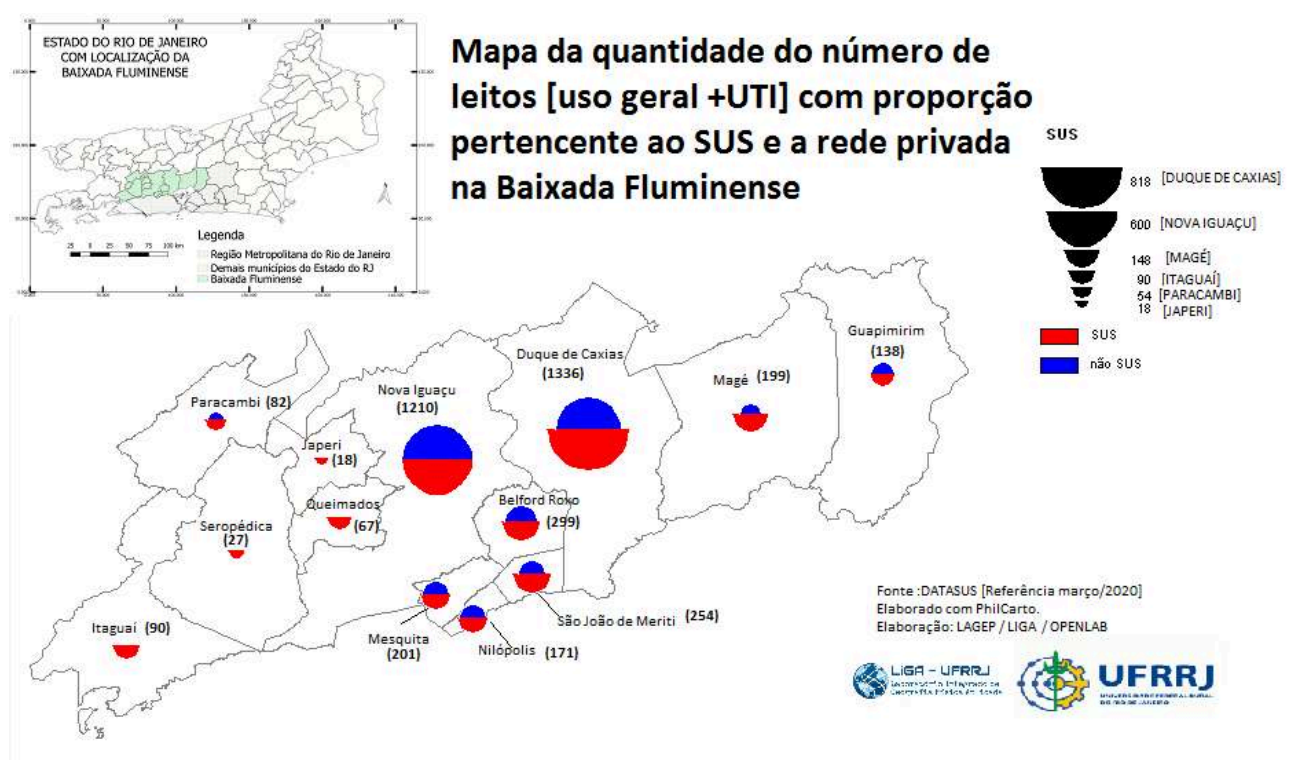

Fonte: DATASUS. Elaboração: LAGEP/LIGA/OPENLAB

37 A espacialidade desde dados revela a concentração dos números de leitos nos municípios com maior centralidade econômica - Nova Iguaçu e Duque de Caxias - e um número muito pequeno de leitos nos municípios localizados mais ao oeste. Percebese também a elevada proporção do número de leitos pertencentes à rede privada que correspondem a mais de $50 \%$ dos leitos em Nova Iguaçu, e se aproxima da metade dos leitos disponíveis em Mesquita, Nilópolis e Belford Roxo. Isso de certa forma caracteriza um quadro de assimetria interna, dada uma elite econômica (caso de Nova Iguaçu) e mesmo parte da classe média que poderia ter acesso a esses leitos privados. Assim, poderíamos pensar que teríamos uma quantidade menor de leitos para a população mais vulnerável e sem acesso aos planos de saúde da rede privada.

Mesmo se considerarmos acesso tanto dos leitos do SUS quanto aos da rede privada o caso ainda permaneceria grave. Quando observamos o mapa da proporção de número de leitos por 1000 habitantes [Imagem 4], são expostas as assimetrias e a seletividade das políticas públicas para o campo da saúde. Por exemplo, Japeri $(0,14)$, Seropédica $(0,32)$, Queimados $(0,44)$, São João de Meriti $(0,53)$, Belford Roxo $(0,58)$, Itaguaí $(0,67)$ e Magé $(0,82)$ possuem menos de 1 de leito por mil habitantes. A realidade mais equilibrada da Baixada é a de Guapimirim, com a média de 2,28 - superando os maiores centros econômicos da região como Nova Iguaçu $(1,47)$ e Duque de Caxias $(1,45)$. 
Imagem 4 - Mapa da Baixada com a relação de número de leitos por 1000 habitantes com quantidade de leitos de UTI

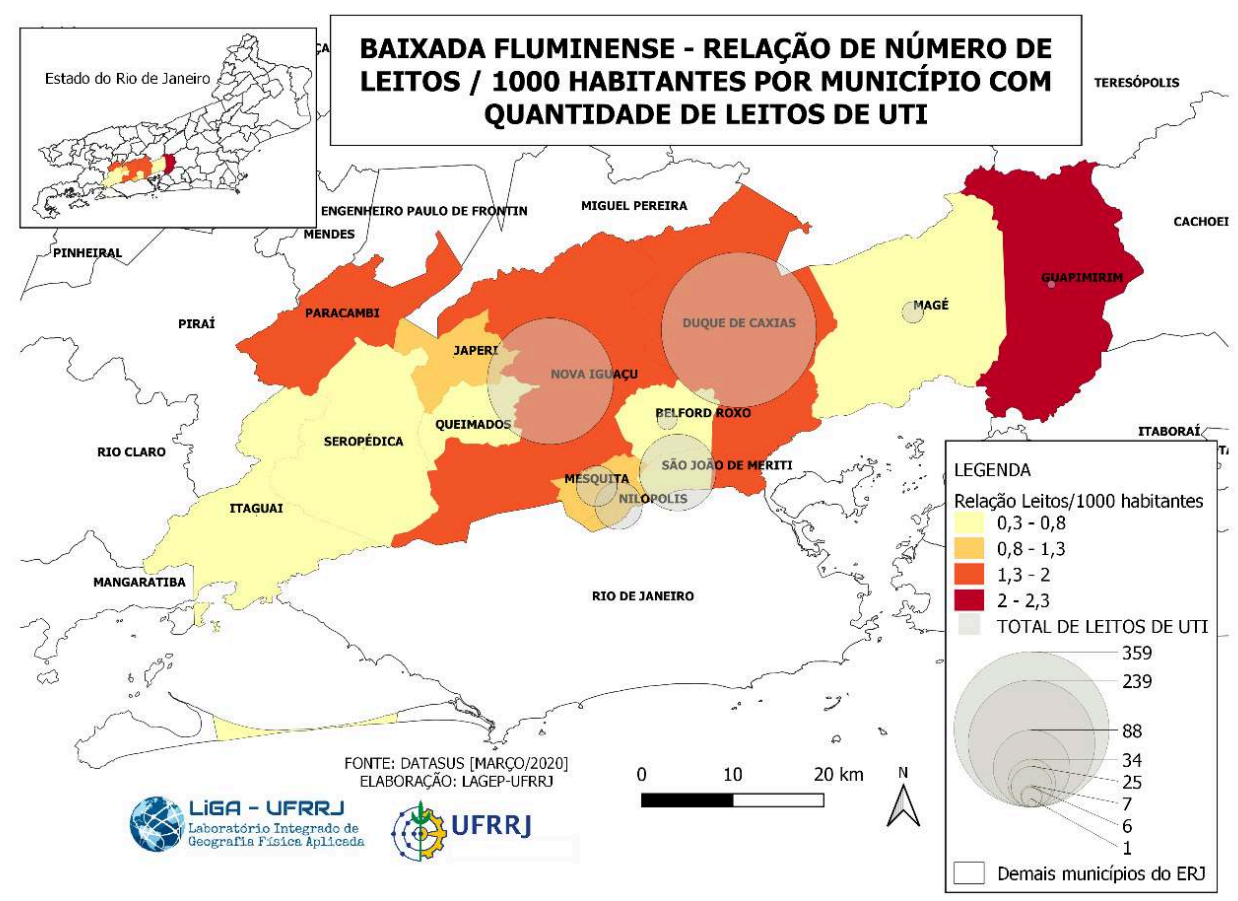

FONTE: DISPONÍVEL EM HTTPS://WWW.PPGIHD-OPEN-LAB.COM/DADOS-BAIXADA? LIGHTBOX=DATAITEM-K8YJHVKS1>

Não se pode ignorar que a maioria dos leitos nestes municípios se encontra em uso por conta de outros tratamentos, como acontece em Nova Iguaçu que, ao final do mês de março, já possuía $80 \%$ de ocupação. Outrossim, não podemos esquecer dos leitos com demanda específica como os destinados à obstetrícia em Mesquita onde, dos 179 leitos de uso geral, 98 são voltados a esta modalidade, ou seja, 55\% dos leitos. Além disso, o CISBAF (Consórcio intermunicipal de saúde da Baixada Fluminense) estima uma falta de sete mil leitos ${ }^{16}$.

Esses dados já colocam o avanço da Covid-19 em estágio de alerta para o sistema de saúde desses municípios, pois tecnicamente esses fatos reduzem a proporção número de leitos por 1000 habitantes e tornam ainda mais dramática a luta contra essa doença.

41 As desigualdades internas da Baixada se aguçam quando observamos apenas o número de leitos de UTI - importantíssimos nos tratamentos dos casos mais graves da Covid-19 que requerem intubação e cuidados mais específicos. Assim, obedecendo a uma "geografia das centralidades", os números totais de leitos de UTI estão concentrados em Nova Iguaçu (239) e Duque de Caxias (359), seguidos por registros em São João de Meriti (88), Nilópolis (34), Mesquita (25), Magé (7), Belford Roxo (6) e Guapimirim (1). Essa espacialização demonstra que municípios situados no extremo oeste metropolitano não possuem leitos de UTI segundo os dados disponíveis no DATASUS. Esses números deixam apenas uma evidência - há uma crise apocalíptica para o sistema de saúde na Baixada no horizonte, algo que pode levar milhares de habitantes ao óbito. 


\section{Algumas conclusões}

A leitura conjunta das informações apresentadas no contexto desta pandemia concretiza como um quadro de assimetrias globais se materializa nas escalas regional e local. Concebida sob os auspícios de um modelo da globalização neoliberal, a forma de gestão das políticas de saúde caminha na contramão das necessidades urgentes das populações, tal como percebemos nas especificidades da Baixada Fluminense.

Por isso concordamos com Milton Santos quando sustenta que a "ordem global busca impor, a todos os lugares, uma única racionalidade” (2002, p.338). Esse modelo de gestão global da saúde, hoje hegemônico, força caminhos privatizantes e reafirma modelos injustos materializados nas realidades locais. Tais modelos estão fadados ao fracasso seja em um contexto de pandemia ou de crise generalizada, seja em condições ditas "normais" para a acumulação capitalista, já que exclui centenas de milhares de pessoas. Como foi visto em grandes epicentros da Covid-19 no mês de março, notadamente Espanha e Itália, percebe-se a clara necessidade da intervenção e participação do Estado no fomento de políticas públicas para a saúde visando sua universalização e maiores danos, em especial sobre as periferias cujos direitos carecem ser reafirmados e garantidos (BARBOSA, 2020).

O efeito do desinvestimento promovido por uma agenda de ajustes fiscais chega na realidade brasileira de forma mais aguda. As regiões urbano-periféricas como a Baixada Fluminense, marcadas por ausências históricas de investimento e gestão eficiente e justa das políticas de saúde, são as primeiras a sofrerem um colapso do seu sistema de saúde. Assim, o desinvestimento que se concretiza em menos hospitais, menos leitos, menos e menos equipamentos reafirma um quadro de injustiças territoriais.

A escalada crescente do número de casos da covid-19 nestes municípios agudiza um quadro de crise no âmbito da saúde. São necessárias políticas públicas para a Baixada Fluminense pensadas em termos éticos e à luz de uma inteligência territorial aptas a atender as condições de vidas de suas populações, e não para afirmar políticas fragmentadoras, privatizantes, clientelistas e individualizadas. Entre as ações, poderíamos citar ao menos duas:

[a] um modelo de gestão ampliada da saúde sob a perspectiva do território. No caso da Baixada, ampliar investimentos nas zonas de maior déficit de número de leitos como acontece com os municípios localizados no extremo oeste da metrópole, e valorizar uma política integrada com ênfase nas ações do CISBAF (Consórcio intermunicipal de saúde da Baixada Fluminense);

[b] integralidade da saúde associada a melhorias da infraestrutura urbana. Neste caso a necessidade de ampliar ações de combate a doenças em consonância a implantação de infraestrutura urbana (saneamento, pavimentação, mitigação de enchentes $\mathrm{e}$ inundações urbanas) aplicada à totalidade dos municípios da Baixada.

Somente desta forma podemos superar uma representação da Baixada Fluminense que ainda insiste em reafirmar as desigualdades e a violência social contra a vida humana e estar preparados para enfrentar crises como a da pandemia do Covid-19. 


\section{BIBLIOGRAFIA}

ANDRADE, Daniel Pereira. O que é o neoliberalismo? A renovação do debate nas ciências sociais. Soc. estado., Brasília, v. 34, n. 1, p. 211-239, Jan. 2019. Disponíevl em <http://www.scielo.br/ scielo.php?script=sci_arttext\&pid=S0102-69922019000100211\&lng=en\&nrm=iso $>$.Acesso em 06 Apr. 2020. 2019. Doi: https://doi.org/10.1590/s0102-6992-201934010009.

BARBOSA, Jorge Luiz. Uma quarentena de direitos para as favelas e as periferias! Espaço e Economia, 17, 2020. DOI : 10.4000/espacoeconomia.10274v

. Cidadania, Território e Políticas Públicas. In: Segundo seminário do Projeto Rio Democracia - caderno de textos. Observatório de Favelas: RJ, 2008. P. 12-14.

BRESSER-PEREIRA, Luiz Carlos. Crise da América Latina: Consenso de Washington ou crise fiscal. <http://bresserpereira.org.br/papers/1991/91-acriseamericalatina.pdf> Data do Acesso. 06/04/2020.

DARDOT, P.; LAVAL, C. La nouvelle raison du monde. Essai sur la société néolibéral. Paris: La Découverte, 2009.

DAVIS, Mike, et al. Coronavírus e a luta de classes. Terra sem Amos: Brasil, 2020.Disponível em: < https://terrasemamos.files.wordpress.com/2020/03/coronavc3adrus-e-a-luta-de-classestsa.pdf.> Data do acesso 10 de abril de 2020.

HAESBAERT, Rogério. Globalização e Fragmentação no Mundo contemporâneo. $2^{a}$ ed. Niterói: EDUF, 2013.

HARVEY, David. O Novo Imperialismo. 3ª ed. São Paulo: Loyola, 2009. . Neoliberalismo: História e implicações. São Paulo: Loyoloa, 2008.

JAMESON, Fredric. Globalização e Estratégia Política. In: SADER, Emir (Org.) Contra Corrente. NLR, o melhor da New Left Review em 2000. Rio de Janeiro: Record, 2001, pp.133-158

MAMIGONIAN, Armen. Qual o futuro da América Latina? In. LEMOS, Amália I. et all.(org's). Questões Territoriais na América Latina. São Paulo:CLACSO/EDUSP, 2006, p. 117-136.

NEGRI, Antonio. Guías. Cinco lecciones em torno a império. Buenos Aires: Paidós, 2004.

OLIVEIRA, Leandro Dias. A emersão da região logístico-industrial do Extremo Oeste Metropolitano fluminense: reflexões sobre o processo contemporâneo de reestruturação territorial-produtiva, Espaço e Economia [Online], 7 | 2015. Disponível em http:// journals.openedition.org/espacoeconomia/1814 ; DOI : 10.4000/espacoeconomia.1814 OMS - Organização Mundial da Saúde. Public Spending on Health: A Closer Look at Global Trends. WHO/HIS/HGF/HFWorkingPaper/18.3 (2018). Disponível em < < https://www.who.int/ health_financing/documents/health-expenditure-report-2018/en/> Data de acesso 06/04/20020.

ROCHA, André Santos da. Os efeitos da reestruturação econômica metropolitana na Baixada Fluminense: Apontamentos sobre o "novo" mercado imobiliário da região. Espaço e Economia: Revista Brasileira de Geografia Econômica, Ano 3, n.ํ 6, Janeiro / Junho de 2015. Disponível em:http://espacoeconomia.revues.org/1677. Acesso em: 10 de dezembro de 2015.

DOI : $10.4000 /$ espacoeconomia.1677

. As representações ideais de um território: Dinâmica econômica e política, agentes e a produção de novos sentidos na apropriação territorial da Baixada Fluminense pós 
1990. Tese (Doutorado em Geografia), PPGG - Programa de Pós-Graduação em Geografia, UFRJ Universidade Federal do Rio de Janeiro, 2014.

.Seletividade espacil das politicas públicas e território urbano- Algumas reflexões. Geo UERJ - Ano 14, nº. 23, v. 1, 2012 p. 99-113.

SANTOS, Milton. Por Uma Outra Globalização. Rio de Janeiro: Record, 2007.

SANTOS, M. O espaço do cidadão. 7ª̣ed. São Paulo: Edusp, 2007(b)

A natureza do Espaço. São Paulo: Edusp, 2002.

SEGADA SOARES, M. T. Nova Iguaçu: absorção de uma célula urbana pelo Grande Rio de Janeiro. In: Revista Brasileira de Geografia. Rio de Janeiro: IBGE, vol2, no24, p.155-256, 1962.

SIMÕES, Manoel Ricardo. Cidades Estilhaçadas. Nova Iguaçu: entrono, 2007.

SOUZA SANTOS, Boaventura de. Pela Mão de Alice. São Paulo: Cortez, 2010.

\section{NOTAS}

1. Segundo o site de notícias da UOL "A informação foi confirmada pelo diretor-geral da OMS, Tedros Adhanom Ghebreyesus, em uma coletiva de imprensa nesta quarta-feira (11/03). Durante a fala, ele destacou que há hoje 118 mil casos em 114 países e que 4.291 pessoas perderam a vida por causa da doença". Disponível em < https:// noticias.uol.com.br/ultimas-noticias/bbc/2020/03/11/coronavirus-oms-declarapandemia.htm> data do Acesso. 06/04/2020.

2. As outras medidas são reforma tributária; juros de mercado; independência do banco central; abertura comercial; investimento estrangeiro direto, com eliminação de restrições; privatização das estatais; desregulamentação (afrouxamento das leis econômicas e trabalhistas); direito à propriedade intelectual. Pra mais informações ver texto de Bresser-Pereira < http://bresserpereira.org.br/papers/1991/91acriseamericalatina.pdf>.

3.

4. Em tradução livre, Gastos públicos em saúde: um olhar mais atento às tendências globais, está disponível em < https://www.who.int/health_financing/documents/health-expenditurereport-2018/en/> Data de acesso 06/04/20020.

5. Tradução livre de "In 2016, the world spent US\$ 7.5 trillion on health, representing close to $10 \%$ of global GDP. The average per capita health expenditure was US\$1,000, but half of the world's countries spent less than US\$350 per person". (OMS, 2018, p.3).

6. Ver informações do relatório da OMS em < https://www.paho.org/bra/index.php? option=com_content\&view=article\&id=5874:paises-estao-gastando-mais-em-saude-mas-pessoasainda-pagam-muitos-servicos-com-dinheiro-do-proprio-bolso\&Itemid=843 >

7. Relatório disponível em < https://nacoesunidas.org/gasto-publico-com-saude-nos-paises-dasamericas-esta-abaixo-do-recomendado-diz-opas/ > Acesso em 07/04/2020.

8. Para maiores detalhes sobre os impactos da desoneração fiscal, sugerimos ve $<$ https:// noticias.uol.com.br/reportagens-especiais/governo-congela-gastos-com-o-sus-enquanto-abremao-de-bilhoes-em-impostos-a-saude-privada\#imagem-2> Data do Acesso 15/04/2020.

9. Trecho retirado da reportagem "Renúncia Bilionária" elaborada por Wanderley Preite Sobrinho e publicada no site Uol. Disponível em < https://noticias.uol.com.br/reportagensespeciais/governo-congela-gastos-com-o-sus-enquanto-abre-mao-de-bilhoes-em-impostos-asaude-privada\#imagem-2> Data do Acesso 15/04/2020 
10. Essa segunda parte do texto foi redigida com base nas informações disponíveis no OPENLAB/ UFRRJ. Idealizado e coordenado pelo professor e Pró-reitor de Pesquisa e Pós-Graduação Alexandre Fortes (UFRRJ), trata-se de um laboratório aberto constituído por uma equipe multidisciplinar (da qual o autor é participante) de pesquisadores e alunos de graduação e pósgraduação vinculados ao PPGIHD e ao PPGGEO da UFRRJ visando o levantamento e a análise de informações sobre o Avanço da Covid-19 na Baixada Fluminense e no Estado do Rio de janeiro, além de cooperar para o conhecimento da população e auxiliar na avaliação e promoção de políticas públicas. Materiais e textos podem ser acessados em < https://www.ppgihd-openlab.com/ >

11. Ver < https://www.ppgihd-open-lab.com/post/covid-19-na-baixada-fluminense-o-tsunamise-aproxima>

12. Boletim de análise de Conjuntura março/abril 2020. O referido Indicador é composto por quatro subíndices: densidade demográfica, faixa etária, infraestrutura sanitária, saúde e mercado de trabalho.

13. Dados atualizados podem ser obtidos no Openlab/UFRRJ < https://www.ppgihd-openlab.com/dados-baixada >.

14.

15. DATA SUS. http://cnes2.datasus.gov.br/Mod_Ind_Tipo_Leito.asp < Data do Acesso 30 de março de 2019

16. Ver reportagem < https://extra.globo.com/noticias/rio/baixada-fluminense-temdeficit-de-sete-mil-leitos-hospitalares-afirma-consorcio-intermunicipal-desaude-22941122.html>

\section{RESUMOS}

O avanço da Covid-19 reafirma a necessidade de repensarmos a gestão e o acesso à saúde no mundo pois, no contexto da globalização neoliberal, ambas são vistas como mercadorias. 0 resultado é o agravamento da pandemia por causa das desigualdades. Devido à progressiva expansão do Covid-19 na periferia metropolitana do Rio de Janeiro, com base em estatísticas e mapas realizamos um diagnóstico que aponta para o colapso iminente do sistema de saúde na Baixada Fluminense.

L'avancement de la covid-19 renforce le besoin de repenser la gestion et l'accès à la santé, devenues des marchandises dans le contexte de la globalisation néolibérale. Le résultat, c'est l'aggravation de la pandémie à cause des inégalités. En raison de l'expansion de la covid-19 vers la périphérie métropolitaine à Rio, on a utilisé des statistiques et des cartes afin de montrer l'imminence du collapse du système de santé dans la Baixada Fluminense.

The spread of covid-19 reaffirms the need for rethinking so management as access to the public and private health systems in the world, for in times of neoliberal globalization both are seeing as goods. As a result, inequalities are increasing the problem of pandemics. Due to the progressive expansion of covid-19 on the Rio de Janeiro metropolitan periphery, I analyzed some statistics and made some maps in order to show the imminent collapse of the health systems in the Baixada Fluminense. 
El avance de Covid-19 reafirma la necesidad de pensar en la gestión y el acceso a la salud en el mundo, que en el contexto de la globalización neoliberal es mirado como una mercancía. Esto aumenta las desigualdades e intensifica el problema de la pandemia. En línea con esta lectura, hicimos un diagnóstico sobre las condiciones en Baixada Fluminense, que señalan el inminente colapso del sistema de salud con la expansión de la pandemia en la periferia metropolitana de Río de Janeiro.

ÍNDICE

Palabras claves: covid-19; políticas del sistema de salud; globalización neoliberal; Baixada Fluminense.

Keywords: covid-19, system of health politics, neoliberal globalization, Baixada Fluminense. Mots-clés: covid-19, politique du système de santé, mondialisation néolibérale, Baixada Fluminense.

Palavras-chave: Covid-19; políticas de sistema de saúde; globalização neoliberal; Baixada Fluminense.

\section{AUTOR}

\section{ANDRÉ SANTOS DA ROCHA}

Universidade Federal Rural do Rio de Janeiro, Programa de Pós-Graduação em Geografia, Laboratório de Geografia Econômica e Política (LAGEP). Email: asrgeo@gmail.com 